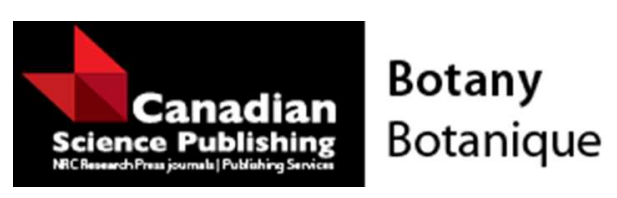

\title{
Application of herb-chronology: Annual fertilization and climate reveal annual ring signatures within the roots of U.S. tallgrass prairie plants
}

\begin{tabular}{|r|l|}
\hline Journal: & Botany \\
\hline Manuscript ID & cjb-2015-0217.R1 \\
\hline Manuscript Type: & Article \\
\hline Date Submitted by the Author: & 23-Jan-2016 \\
\hline Complete List of Authors: & $\begin{array}{l}\text { Dee, Justin; oklahoma state university, botany } \\
\text { Palmer, Michael; oklahoma state university, botany }\end{array}$ \\
\hline Keyword: & $\begin{array}{l}\text { Annual RIngs, Herb-Chronology, Grasslands, Interannual Climatic } \\
\text { Variability, Fertilization }\end{array}$ \\
\hline & \\
\hline
\end{tabular}

SCHOLARONE ${ }^{\text {T }}$

Manuscripts 
Dee, J. D. and Palmer, M. W. Application of herb-chronology in the U.S. tallgrass prairie

Application of herb-chronology: Annual fertilization and climate reveal annual ring signatures within the roots of U.S. tallgrass prairie plants

Justin R. Dee and Michael W. Palmer

Dee, J.R. (Corresponding author, jrdee@okstate.edu): Department of Botany, Oklahoma State University, 301 Physical Science, Stillwater, Oklahoma 74078. Palmer, M. W. (Mike.Palmer@okstate.edu) 
Dee, J. D. and Palmer, M. W. Application of herb-chronology in the U.S. tallgrass prairie

\begin{abstract}
The relatively new field of herbaceous root chronology ("herb-chronology") uses annual rings of secondary xylem in roots of perennial forbs to analyze belowground secondary growth as a function of annual growth environment. By using three tallgrass forb species from long-term experiments within Konza prairie of northeastern Kansas USA, we aim to find the effects of fertilization, growing season temperature, and precipitation on annual secondary growth. For two of the three species, we found annual rings were significantly larger between plots that were fertilized annually with phosphorus or nitrogen + phosphorus in contrast to unfertilized control plots. Rings also had significant variation with climatic variables. We found a consistent negative correlation with early season temperature for each species. However, early growing season precipitation proved to be far less consistent, with positive correlations only found in a few cases between species. Overall, we conclude that annual rings in these select tallgrass prairie species may not carry reliable climatic signatures; rather site-specific ecological factors, such as aboveground competition with neighbors, may be more important for annual ring patterns. In our discussion we propose a framework to help better disentangle the effects of site or climatic factors that may affect herbaceous annual ring variation.
\end{abstract}

Keywords: Annual rings, herb-chronology, grasslands, interannual climatic variability, fertilization, supplemental water 
Dee, J. D. and Palmer, M. W. Application of herb-chronology in the U.S. tallgrass prairie

\section{Introduction}

Annual growth rings in the secondary xylem of plants may be useful for linking past environmental conditions with annual growth. In the field of dendrochronology, annual ring widths from tree stems can be used in reconstructing long-term climatic histories from a diversity of time periods and plant communities worldwide (Conkey 1986; Matisons et al. 2012; Voelker et al. 2012). In addition to climatic reconstruction, annual rings are also useful for investigating stand history. For instance, a gradual decline in ring width helped resolve when exotic woody species first established and suppressed growth of natives in Ohio hardwood forests (Hartman and McCarthy 2007), or how severe drought limited growth of dominant canopy species in Mediterranean forests (Corcuera et al. 2004). Conversely, a gradual increase in annual growth could pinpoint the timing of community-wide disturbance events, which released growth and initiated succession of Appalachian old growth forests (Abrams et al. 1998; Hart et al. 2012).

Though dendrochronology is a valuable tool for vegetation science, it is only confined to studying the growth of species with perennial aboveground woody tissue. However, studying the growth of non-graminoid herbaceous species is just as important since herb species represent key components of grassland systems responsible for a major part of global net primary production (Hui and Jackson 2006). Being that annual net primary production in many grasslands is largely a function of annual climatic and site ecological factors (Knapp and Smith 2001), a technique similar to the study of rings in woody species is needed to investigate how yearly ecological and climatic conditions may impact plant growth and production in herbaceous species. Fortunately, certain techniques to monitor past growth may be applied to herbaceous species by using the annual rings of the secondary xylem within the taproot or rhizome of perennial forb species: a technique coined 'Herb-chronology' by Dietz and Ullmann (1998). 50 to 85\% of all forb species sampled possess fairly to clearly demarcated growth rings (Dietz and Ullmann 1997). In the majority of cases these growth rings are found to be annual (von Arx and Dietz 2006). To date, the most common herb-chronology research is counting rings to assess population age structure (Dietz and Ullmann 1998; Dietz 2002; Pergl et al. 2006; Perkins et al. 2006).

In many respects herb-chronology has not reached its full potential. Dietz and Schweingruber (2002) stated that there is a lack of knowledge about annual growth rings in North American perennial forbs; since its beginning herb-chronology research has focused 
primarily on Central European grasslands. Furthermore, the true potential of using annual rings outside of population level studies, such as indicators of climatic or site-specific ecological factors, have only begun to be explored. Only a few studies in herb-chronology address these issues: For instance, Dietz and Ullmann (1998) unlocked past site history by discovering decreasing annual ring widths of herb species along a gradient of shade within an encroaching shrub. Dietz and von Arx (2005) found synchronous interannual variation in ring widths of perennial forbs across Europe and North America that were a function of El Niño Southern Oscillation (ENSO). In addition, Liu and Zhang (2010) found the same associations between ENSO and perennial forb root increments in an inner Mongolian grassland. Considerable amount of work has also been done linking alpine perennial forb annual ring increments to climatic conditions of the high altitudes, notably interannual variation in snowpack and/or drought (Dietz et al. 2004; Franklin 2013).

The tallgrass prairie of the central U.S. provides great potential for further exploring the possible site ecological and regional climatic signals perennial forbs may hold in their annual rings. Fire, mowing, and fertilization represent land management practices that affect annual production of these grasslands (Collins et al. 1998; Knapp and Seastedt 1998), which may influence annual ring width variation. In addition, these mesic systems have experienced great fluctuation in annual precipitation in the last few decades (Zhou et al. 2012), thus affecting productivity (Knapp and Smith 2001). However, little is known about the determinants of belowground annual production in prairie plants (Hui and Jackson 2006; Xu et al. 2012). Considering that about half of grassland net primary production is from belowground organic matter in the form of root biomass (Luo et al. 2009), any fluctuation in this belowground production could be important in sequestering carbon to long-term belowground sinks (Zhou et al. 2012), especially if annual belowground biomass production is tied to yearly aboveground production.

Using preexisting research plots with imposed treatments, we ask the following questions: 1. How do different levels of annual fertilization affect the annual ring width? 2. How does supplemental irrigation affect the annual ring width? 3. How do average monthly temperature and precipitation in different parts of the growing season relate to ring width? 4. How does the pairwise correlation of annual rings compare between site-specific ecological 
Dee, J. D. and Palmer, M. W. Application of herb-chronology in the U.S. tallgrass prairie

factors (intra-treatment correlation) and possibly the regional climate (inter-treatment correlation)?

\section{Materials and methods}

\section{$\underline{\text { Study site and LTER experiment descriptions }}$}

Konza Prairie Biological Station (KPBS) is part of the National Science Foundation's Long Term Ecological Research (LTER) network and is jointly owned and operated by Kansas State University and The Nature Conservancy. Located on approximately 3,487 hectares of native tallgrass prairie in the Flint Hills region of northeastern Kansas $\left(39.0833^{\circ} \mathrm{N}, 96.5833^{\circ} \mathrm{W}\right)$, Konza Prairie's LTER program consists of numerous long-term studies focusing on fire, grazing, and climatic studies and their impact on the structure, function, and composition of native tallgrass prairie vegetation. $\mathrm{C} 4$ grasses typical of undisturbed native tallgrass prairie dominate this area, consisting predominately of Andropogon gerardii (Big bluestem), Schizachyrium scoparium (Little bluestem), Sorghastrum nutans (Indiangrass), and Panicum virgatum (Switchgrass) (Freeman 1998). Forb species have lower biomass but contribute substantially to the diversity of the region (Turner and Knapp 1996). Mean annual air temperature at KPBS is 13 ${ }^{\circ} \mathrm{C}$ with the late summer months ranging from $20-33{ }^{\circ} \mathrm{C}$ and late winter months ranging between -9- $3{ }^{\circ} \mathrm{C}$ (Nippert and Knapp 2007). Average annual precipitation of the station is $835 \mathrm{~mm}$, to which about three fourths of this coincides with the late spring and early summer of the growing season (Hayden 1998).

We utilized two ongoing experiments initiated in 1986. The first such experiment, titled "the belowground plot experiment" (Rice et al. 1998), monitors the interactive effects of annual mowing, burning, and fertilization on aboveground net primary production (ANPP), belowground net primary production (BNPP), plant species composition, plant N and P content, decomposition, soil chemistry, and soil biota composition. In total there are $6412 \mathrm{~m}^{2}$ plots set up in a split-plot design with main blocks arranged by fire treatment and further subdivided by mowing and fertilization treatments. Burning and mowing treatments are either plots that are burned and/or mowed once on an annual basis or plots that remain as unburned and/or unmowed control plots. It is important to note that mowing treatments were discontinued in 2003. 
Dee, J. D. and Palmer, M. W. Application of herb-chronology in the U.S. tallgrass prairie

Fertilization consisted of four treatments: an unfertilized control $(\mathrm{C})$, nitrogen only $(\mathrm{N})$, phosphorus only $(\mathrm{P})$, or a nitrogen + phosphorus nutrient $(\mathrm{N}+\mathrm{P})$ addition. There are four replications of each of the 16 possible treatment combinations for a total of 64 plots. Annual burns are implemented every late June while fertilization is applied by hand broadcasting annually in early June using the following treatments: $\mathrm{N}=10 \mathrm{~g} \mathrm{~N} \cdot \mathrm{m}^{2}$ as ammonium nitrate, $\mathrm{P}=$ $1 \mathrm{~g} \mathrm{P} \cdot \mathrm{m}^{2}$ as superphosphate, and $\mathrm{N}+\mathrm{P}=10 \mathrm{~g} \mathrm{~N} \cdot \mathrm{m}^{2}+1 \mathrm{~g} \mathrm{P} \cdot \mathrm{m}^{2}$ (Rice et al. 1998).

The second experiment is a water supplementation study (Knapp et al. 1994), identified as the "irrigation transects experiment," where the amount of water supplied is set to meet expected evapotranspirational demands per year. Watering events are contingent upon the timing of precipitation events, but usually are at the highest frequency during the late summer where precipitation is relatively low and temperatures the highest. Two 100-meter long irrigation lines span from the top of a rocky hillside down to lowlands below at a medium slope gradient.

Twelve 1.5 meter tall high impact sprinkler heads are located at equal distance along the irrigation lines, with a spray rate of $8 \mathrm{~mm} /$ hour to a radius of 15 meters from the head (Knapp et al. 1994). Each 100 meter irrigated span serves as a transect where water status of the most dominant grass species is measured on an annual basis, along with ANPP, within the three meter zone of maximum spray coverage of each individual sprayer (Knapp et al. 1994). Control transects that are also 100 meters long are located adjacent to each irrigation transect, but out of the spray zone of adjacent irrigation treatments.

\section{$\underline{\text { Field and laboratory methods }}$}

In early September 2013, we visited the two experimental sites located at Konza Prairie and assessed which species provided frequent enough abundance amongst the different treatments. The overall focal species in our study were Asclepias syriaca, Dalea purpurea, and Lespedeza capitata. A. syriaca is a member of the milkweed family (Apocynaceae), with a root system that appears to be a rhizome, and an erect aboveground shoot that can reach about two meters in height. D. purpurea and L. capitata (both Fabaceae) are both taprooted perennials with multi-branched aboveground shoots that may reach at a maximum of 1.5 meters in length. KPBS represents the middle latitude in all three of the respective species ranges. D. purpurea and $L$. capitata, were found exclusively in plots that were burned annually while $A$. syriaca was too infrequent in unburned plots to have a sufficient sample size between burn treatments. Thus, for 
Dee, J. D. and Palmer, M. W. Application of herb-chronology in the U.S. tallgrass prairie

each species, we could not test between the burn treatments. Additionally, mowing treatments, which ceased in 2003, could also not be evaluated since the average number of rings was fewer than ten.

The analysis of the fertilization experiments consisted of comparisons between $\mathrm{N}+\mathrm{P}, \mathrm{P}$, and $\mathrm{C}$ treatments for A. syriaca and comparisons between $\mathrm{P}$ and $\mathrm{C}$ treatments for L. capitata and D. purpurea. Replication amongst treatments was possible since species abundance was high enough between four, and in some cases five, replicates for each treatment for all three species. Up to five individuals per species were collected by sampling individuals closest to each of the four corners and center per plot, thus making the total sample size for each fertilization treatment between 20-25 individuals. The root collar (represented as the area directly beneath the root crown where previous shoots originated), was located and harvested after digging typically $1-5$ $\mathrm{cm}$ belowground, but in some cases as far as $10 \mathrm{~cm}$ below the surface. It should be noted however, that the 'root' collar for $A$. syriaca was probably anatomically stem material since in all cases it contained pith. For the irrigation transect, L. capitata was the only species abundant enough in treatment and control transects. Furthermore, we decided to only collect individuals from lower parts of the transect since $L$. capitata was nearly non-existent upslope. The same excavation methods were applied with sample size $n=20$ per each transect (one irrigated and one control). We paid careful attention to collecting only individuals that were within the zone of even coverage from each sprayer along the irrigation transect.

Laboratory methods consisted of using a sledge microtome to cut approximately 20-30 $\mu m$ thin sections of each root collar that were then stained with Toluidine Blue for 5 minutes. Toluidine Blue is a metachromatic dye for staining lignified structures. Thus, in a microsection stained lignified secondary walls of fiber cells in the latewood would be an indicator for discerning one annual ring to the next (see Figure 1). After the staining process was complete, specimens were photographed with a low power dissecting scope with a Leica digital camera. Magnification levels were noted for each image, along with a photographed $1 \mathrm{~mm}$ scale for calibration. This subsequent analysis for measuring ring widths was performed in ImageJ (Abramoff et al. 2004) using the image stitching tool when necessary (Preibisch et al. 2009) and the line segment measuring tool. Ring widths were averaged across three radii that were each subjectively chosen to represent the variation in diameter along the span of each ring as accurately as possible. 


\section{$\underline{\text { Analytical Methods }}$}

Ring borders were identified by the proliferation of earlywood- like vessels, which are larger in area and higher in density, adjacent to the previous season's latewood, which for all species consisted of relatively few vessels. After ring widths were measured on each individual, we were able to construct the presumed age at time of sampling by counting total rings present, though we do note that this was not possible for all individuals since the more aged part of the root collar for about half of the individuals was too deteriorated to delineate ring boundaries. Since traditional age-detrending was not possible because there were few rings per individual, we decided to use age in 2013 as a covariate (for ones that had deteriorated older parts, we used the maximum amount of rings visible) when we applied ANCOVAs to test the variation in ring widths amongst the fertilization and irrigation treatments for each separate year. Due to the fact that most of individuals were between $3-6$ years old at the time of sampling, as well as the sizable portion of individuals who had deterioration of the central root which blurred the older ring boundaries, we usually carried the analysis to either 2007 or 2008 since any year before these had considerably reduced sample sizes. Additionally, we used Tukey's post hoc comparisons for the three fertilization treatments with Asclepias syriaca. Obtaining historical climatic data from Konza's Climate Reference Network, we also took the average monthly temperature and precipitation between April and June and also July through September per year to test the climatic signal on ring width from either the early or late growing season. We used Pearson correlation to test between all ring widths per each species and experiment separately using these climatic variables. Finally, to detect the strength of intra- or inter-treatment correlations amongst individuals, we used macro functions in Microsoft Excel to calculate yearly pairwise correlations between series. From this analysis, the average correlation between series was calculated per treatment to determine intra-treatment correlations. To find the inter-treatment correlations using this technique we simply found the average correlation between series with all treatments included as a whole.

\section{Results}


Dee, J. D. and Palmer, M. W. Application of herb-chronology in the U.S. tallgrass prairie

Growth rings were easily discernable for the three species in the study (Fig. 1). We assume that growth rings are annual for these three species since, upon excavation (late summer), the ring closest to cambium was always past the typical "earlywood" phase and somewhere in the "latewood" phase. Overall sample sizes decreased after transport from the field due to a handful of roots suffering from decomposition due to mold spore attack during transport. This highlights the importance of storing roots in a high enough concentration of alcohol during transport, at least in $40 \%$ ethanol is adequate (Schweingruber et al. 2011). As previously mentioned, a considerable amount of the roots were also decomposed in the older parts of the organ, rendering confident aging of these individuals too difficult to include in analyses. Though we cannot show the age distribution for our study we do highlight the sample depth per year pertaining to each experiment (Figure 2).

Overall, fertilization treatments had significant effects on annual ring width for the focal species of the belowground plots experiment, with the exception of D. purpurea (Data for D. purpurea are not shown). In A. syriaca, the years 2012, 2013, and average of all years combined had significant variation amongst treatments, with the general pattern of ring widths increasing from $\mathrm{C}<\mathrm{P}<\mathrm{N}+\mathrm{P}$. For 2012 the only significant difference was $\mathrm{C}$ being significantly less in average width than $\mathrm{N}+\mathrm{P}(\mathrm{F}$-test $=3.59, \mathrm{df}=2, P<0.03$, Fig. 3a), while for 2013 both $\mathrm{C}$ and $\mathrm{P}$ were significantly less than $\mathrm{N}+\mathrm{P}(\mathrm{F}$-test $=3.32$, $\mathrm{df}=2, P<0.04$, Fig. 3a). Though there were no significant differences between fertilization treatments from $2007-2011$, when all years are combined, $\mathrm{C}<\mathrm{NP}$ was the overall significant difference $(\mathrm{F}-\mathrm{test}=5.39 \mathrm{df}=2, P<0.01$, Fig. 3a). For L. capitata, the years 2011-2013 and overall averages had significant differences between $\mathrm{C}$ and $\mathrm{P}$ treatments, with $\mathrm{C}<\mathrm{P}$ in each year $(\mathrm{F}$-test $=2.81$, $\mathrm{df}=1, P<0.001$ (2013), F-test $=2.21$, $\mathrm{df}=1, P<0.02$ (2012), F-test $=1.72, \mathrm{df}=1, P<0.05$ (2011), and F-test $=2.12, \mathrm{df}=1, P<0.04$, (all years) respectfully, Fig. 3b). D. purpurea was the only species of the three to not have any fertilization treatment effect on annual rings. The irrigation transects yielded less clear patterns, with the control transects holding significantly larger rings than irrigated transects in 2008 and 2010 for $L$. capitata $($ F-test $=4.41, \mathrm{df}=1, P<0.04$, Fig. 4$)$ only.

Climatic variables had significant correlations with annual ring increment of each of the three focal species in both experiments, however, the overall patterns were weak with rather small magnitudes of effect. For all 3 species a negative correlation with mean monthly temperature between April and June was significant in the belowground plots by using all years 
Dee, J. D. and Palmer, M. W.

Application of herb-chronology in the U.S. tallgrass prairie

pooled together $(\mathrm{P}<0.05)$ : A. syriaca had a coefficient of $-0.184(\mathrm{df}=288, P<0.001$, Fig. 3a), L. capitata had a coefficient of -0.217 ( $\mathrm{df}=183, P<0.001$, Fig. $3 \mathrm{~b}$ ), and D. purpurea had a coefficient of $-0.231(\mathrm{df}=184, P<0.001)$. L. capitata also had a negative association with monthly temperature between April and June in the irrigation transects $(r=-0.223, \mathrm{df}=172, P<$ 0.003, Fig. 4). For monthly precipitation amount, average precipitation between April and June proved to be positively correlated with $D$. purpurea ring width in the belowground plots $(r=$ $0.206, \mathrm{df}=184, P<0.004)$ and also $L$. capitata in the irrigation transects $(r=0.227, \mathrm{df}=172, P$ $<0.002$, Fig. 4).

Table 1 shows the intra- and inter-treatment correlations per species. We considered a strong mean pairwise correlation coefficient to be $>+0.500$, which is the minimum accepted value typically used in dendrochronology for accurate cross-dating of ring series (Cook 1983). Overall, the only species to have consistently strong intra-treatment correlations for the fertilization treatments was L. capitata. The inter-treatment correlation was also relatively strong for L. capitata (0.5212, Table 1). For A. syriaca and D. purpurea within and amongst the fertilization treatments, the pairwise correlation was usually close to zero, thus showing weak series intercorrelation of annual rings towards the treatment. Lastly, L. capitata had overall weak series intercorrelation within and amongst the irrigation transects with pairwise correlations usually close to zero.

\section{Discussion}

Annual rings in our study were more consistently related to fertilization than to interannual climatic variation. We found a positive relation between fertilization and annual ring widths for two of our three species studied while climatic factors only amounted to weak relationships with ring variation. Specifically, we found a consistent negative correlation between early season temperature and ring width in conjunction with a more inconsistent positive relation with early season precipitation. The weak patterns with climate are further exemplified with overall weak inter-treatment correlations we found with each species. Though intra-treatment correlations were inconsistent in overall magnitude as well, the only ones that were strong were related to fertilization treatments for L. capitata. 
Dee, J. D. and Palmer, M. W. Application of herb-chronology in the U.S. tallgrass prairie

The general correspondence with fertilization compared to climate is discussed in the context of annual ring ontogeny in this discussion. We suggest that ring width variation may be a function of an internal carbon budget based on yearly competition for resources. The source of this yearly variation in competition is thought to be modulated by variation in interannual climate. Throughout this discussion, we suggest a framework for improving future herbchronology studies aimed at matching annual ring signatures with past growth environment.

Physiological determinants of the relationship between belowground secondary growth and site $\underline{\text { conditions }}$

Annual incremental growth of the root secondary xylem could be a function of conductance to sustain aboveground growth (von Arx et al. 2012; Olano et al. 2013) and enlargement to make storage room for photoassimilates (Bell and Ojeda 1999; Lacointe 2000). While specific changes in soil moisture and evaporative stress may impact the size and distribution of conductive tissues in the root annual ring (von Arx et al. 2012; Olano et al. 2013), the amount of metabolically expensive storage space (Chapin et al. 1990; Salisbury and Ross 1992) created in annual rings may be more tied with the overall carbon budget of the plant and competition between different carbon sinks (Wardlaw 1990). In fact, von Arx et al. (2006) found evidence that the timing of reproduction with a plant's life history could have an overall effect on ring width, likely due to the cost of reproduction on total carbon budget. Overall, the production and allocation of photoassimilates leading to belowground secondary growth could be strongly related to immediate growth conditions of the site, plant life history, and carbon budget.

The tallgrass prairie is seen as nitrogen limited, especially when annually burned (Ojima et al. 1994). Specifically with $A$. syriaca, we found that the Nitrogen + Phosphorus addition had on average the largest rings, perhaps from increased aboveground photosynthetic rates. On the other hand, individuals in control plots, in what can be seen as relatively $\mathrm{N}$ limited, had comparatively decreased ring sizes. Allocation to increased fine root biomass or any other organ may outcompete allocation towards belowground carbon sinks in this limiting condition (McCarthy and Enquist 2007). Furthermore, the strength of allocation competition between sinks may be inconsistent between individuals in this condition, which could explain the lack of pairwise correlation within lower level fertilization treatments for $A$. syriaca. In fact, A. syriaca is a rhizomatous species, which could help further explain the lack of pairwise correlations 
Dee, J. D. and Palmer, M. W. Application of herb-chronology in the U.S. tallgrass prairie

amongst individuals. Rhizomatous species should be analyzed with caution since the spatial spread of the plant as a whole may considerably differ between individuals. Thus, it may be hard to attribute ring variation to any treatment related factors if annual rings could be more sensitive to the conditions outside of the treatment area where a significant proportion of the plant may exist. Unfortunately, this may be a factor in our study, as it was part of the sampling design to choose plants close to the four corners of the treatment plots. If analyzing rhizomatous species, future studies should only sample individuals well within treatment boundaries.

L. capitata, one of the two nitrogen fixers in our study, had the greatest positive magnitude of effect from increased fertilization. Interestingly, L. capitata only occurred in annually burned control and phosphorus plots. Other closely related legume species are found to have increased frequency in burned areas (Towne and Knapp 1996), possibly due to a selective advantage these nitrogen fixers may have over non-nitrogen fixers in annual burned areas that become extremely nitrogen limited (Lauenroth and Dodd 1979; Ojima et al. 1994). The increased frequency of $L$. capitata in the phosphorus treatment may be because of the putative role of phosphorus in increasing rates of nitrogen fixation (Sprent and Raven 1985; Aerts and Chapin 2000; Reed et al. 2007), which is usually concomitant with increased rates of foliar biomass production in pastoral legume species (Ae et al. 1990; Smith 1992; Ayala et al. 2000). Increased ring size in phosphorus addition plots could be the result of the increased need for storage under higher rates of photosynthetic activity. The suggested physiological role that fertilization plays on increasing rates of nitrogen fixation could be driving the relative higher intra-treatment pairwise correlations for L. capitata. In this aspect, phosphorus addition may lead to a more consistent response in growth between individuals.

In contrast, considering D. purpurea's lack of response to fertilization, biomass responses to nitrogen limitation and/or phosphorus availability may not be consistent between all legumes, as Towne and Knapp (1996) found in similar legume fertilization studies. In fact, increased nitrogen inputs may even negatively affect the legume-rhizobium mutualism and result in decreased foliar biomass in some legumes (Weese et al. 2015). The extent to which this negative reaction may exist may highly differ from plant to plant, possibly explaining the weakness of intra-treatment pairwise correlation we found with D. purpurea.

Given the overall positive impact fertilization had on ring sizes in our study, any future herb-chronology studies aiming to further connect ring width with aboveground productivity 
Dee, J. D. and Palmer, M. W. Application of herb-chronology in the U.S. tallgrass prairie

must consider a suite of additional factors to measure. Namely, closer observation between the correlative response between foliar biomass, reproductive biomass, photosynthetic rates, and secondary annual growth will help solidify the utility of using annual rings as markers of past site conditions and plant productivity. Furthermore, as seen with the inclusion of nitrogen fixers in our study, life history traits of individual species under study should be taken into consideration. Overall differences in physiology may play an important role in the patterns of annual ring variation related to site conditions.

Using series intercorrelations to determine the strength of common signals between different trees and the possible sensitivity to environmental factors is a common practice in dendrochronological research. Thus, for future herb-chronology studies we also strongly recommend incorporating pairwise correlation analysis, as we did in this study, to calculate series intercorrelations within different environmental conditions between sites within a study. One primary reason for doing so is that it will strengthen confidence that all series were properly cross-dated. An additional strength could be determining the relative ease of cross-dating for any one specific species, which could be particularly useful for herb-chronology where it is not yet known the extent to which root growth rings are indeed annual across species.

However, we do caution that pairwise correlation for climatic analysis should only be considered for longer lived individuals, where the majority of samples are at least 20 years old. Due to a likely low sample depth of earlier years, cross-dating using pairwise correlation likely becomes unreliable with anything less than 20 years old if the overall goal is to carry out proper correlative analysis with climate, including using such linked indices as "mean sensitivity" (Fritts 1976) and the "expressed population signal (EPS)" (Briffa and Jones 1990). Longer chronologies such as the work of Franklin (2013) and her 77 year-long chronology of a longlived U.S. alpine herb, have done this effectively by using the afore mentioned indices in finding associations between ring width and climate. Nonetheless, for future studies with relatively short chronologies such as ours, intra- and inter- treatment pairwise correlation still has its advantages within and amongst sites that represent particular extremes in a persistent environmental condition. Strong intra-treatment pairwise correlations in this aspect could lead to considerable support of which environmental factors are most important in affecting annual ring sizes in short lived herbs. Correlations with interannual climate can still be done by using a rather short master 
Dee, J. D. and Palmer, M. W. Application of herb-chronology in the U.S. tallgrass prairie

chronology though we discuss potential pitfalls, as they were evident in our study, in the proceeding sections.

The suspected effect of competition on annual ring variation and the interactive effects with $\underline{\text { climate }}$

In the tallgrass prairie, aboveground biomass of dominant grass types responds positively to annual precipitation. However, foliar grass biomass is negatively correlated with aboveground biomass of forb species (Briggs and Knapp 1995). In our study, we observed overall patchy distributions of large grass cover between experiments. The irrigated transects had visually more cover of dominant grasses than the nearby controls, as did unfertilized plots compared to ones that had fertilization. The weak relationship between precipitation and annual ring width could be because of the unequal presence of dominant grass species and their potential inhibitory effects on forb biomass production in wetter environments (Briggs and Knapp 1995). Reduced photosynthetic output from aboveground competition could lead to less allocation to belowground carbon sinks (Bloom et al. 1985; Chapin et al. 1990), and obscure the otherwise positive effect of precipitation on ring growth.

Overall hotter years bring about overall lower amounts of annual net primary productivity in North American grasslands (Knapp and Smith 2001; Knapp et al. 2002), especially in annually burned tallgrass prairie (Briggs and Knapp 1995). Though hotter temperatures could lead to a declined growth environment for forbs in general, competition with grasses could be amplified when high temperatures lead to increased evaporative stress. In an already stressful growth environment, forb species would have to simultaneously compete with dense superficial roots of neighboring grass for water (Kiaer et al. 2013). Thus, it shouldn't be surprising that we found a consistent negative relationship between temperature and ring size in our study. However, the overall patchy distribution of grasses may play a role in the weak pairwise correlations nonetheless.

Future studies may benefit from experimentally disentangling the apparent interaction between climate, competition, and their effects on belowground secondary growth in perennial forbs. In addition, since juvenile tree seedlings have a considerable difference in the factors they respond to in comparison with adult trees regarding their annual rings (see Mendivelso et al. 2013 for example), herb-chronology studies should also consider age as an additional factor 
Dee, J. D. and Palmer, M. W. Application of herb-chronology in the U.S. tallgrass prairie

when investigating rings in perennial forbs and how they respond to the environment. We attribute the lack of consistent pattern between ring width and the earlier years under analysis in our study to this possibility of juvenile sensitivity. Thus, experimentally manipulating competition levels in concert with the natural variation in interannual climate, as well as considering age as a factor, should help in determining the relative importance of site ecology and climate on annual ring variation. As before, we also suggest using pairwise correlations within and amongst treatments in this suggested experimental design. Strong pairwise correlations within an induced level of competition may give a reliable indication of importance of competition on ring growth. On the other hand, if there were a stronger inter-treatment correlation then this could warrant further investigation into correlative analysis with climate and its putative role on interannual ring variation.

\section{$\underline{\text { Conclusions }}$}

Well-established fields such as dendrochronology have used annual growth rings to uncover the effects of past ecological and climatic events on the growth of woody plant populations in a variety of landscapes (Corcuera et al. 2004; Hartman and McCarthy 2007). Since herbaceous species constitute some of the biggest epicenters of belowground primary production (Luo et al. 2009), the field of herb-chronology warrants further investigation into whether or not annual rings in roots may be records of past site and climatic factors that affect plant production. In addition to a few other earlier herb-chronology studies, our work represents one of the first attempts to relate annual ring variation in herbaceous species with site growing conditions and/or interannual climate (Dietz et al. 2004; Dietz and von Arx 2005; Liu and Zhang 2010; Olano et al. 2011; Franklin 2013). Of these studies, ones with moderate length chronologies (at least ten years on average) found significant correlation between interannual ring variation and yearly climate (Dietz et al. 2004; Dietz and von Arx 2005; Liu and Zhang 2010). In our case however, our overall chronology can only be applied to the six year period between 2007 - 2013, where we found only weak associations with climate. Though this is a limitation in our study, we still advocate for future herb-chronology research in the U.S. tallgrass prairie region, being aware of the possibility of root rot, but also taking the initiative to investigate other perennial forbs which may possess longer chronologies in this diverse grassland environment (Briggs and Knapp 1995). 
Dee, J. D. and Palmer, M. W. Application of herb-chronology in the U.S. tallgrass prairie

Nonetheless, we found consistent relationships between fertilization and annual ring variation coupled with the weak association with yearly climate. Besides the fact that our overall chronology may have been too short to pick a stronger climatic signal, the patchy distribution of grasses in our study and our weak correlations with climatic factors could also point to the possible greater role of competition on annual ring growth increments. To further disentangle site ecology from climate, we suggest future studies utilize experimental frameworks manipulating certain site factors and using pairwise correlations to find whether site or climate (for chronologies of at least 20 years old) is the driving force behind annual ring variation. While we believe that weak pairwise correlations were attributable to the ecological factors previously mentioned, we highlight the possibility of false annual ring occurrence, which can lead to incorrect year assignments. Careful attention needs to be paid towards recognizing ring patterns in a selected target species (see Schweingruber et al. 2011 for a good visual reference to many plant families). If possible, verifying if the growth rings are indeed annual should always be the first step.

We also strongly recommend future studies incorporating physiological aspects on the individual plant level to better understand how annual rings in the roots of herbaceous species correspond to aboveground biomass and how this may differ between life history groups. In this aspect, age should also be considered as the juvenile stages of a plant may be more sensitive towards different environmental factors than older more mature individuals may be. Overall, if some of these improvements to herb-chronology research take place in future studies then the true potential of this emerging discipline in vegetation science may be realized.

\section{Acknowledgements}

We would like to thank Dr. John Blair of Kansas State University for facilitating the use of Konza Prairie Biological Station for means of this study, as well as Sue McAlister, Ky Shen, Janette Steets, AJ Harris, and the anonymous graduate students who partake in the OSU Academic Document Exchange program for various recommendations involving the earlier stages of this manuscript. We also thank the anonymous reviewers for with their recommendations improving the publication of this work. This study was not funded by any significant exterior contributions. 
Dee, J. D. and Palmer, M. W. Application of herb-chronology in the U.S. tallgrass prairie

\section{References}

Abrams, M.D., Ruffner, C.M., and DeMeo, T.E. 1998. Dendroecology and species co-existence in an old-growth Quercus-Acer-Tilia talus slope forest in the central Appalachians, USA. Forest Ecology and Management 106(1): 9-18.

Abramoff, M.D., Magalhaes, P.J. and Ram, S.J. 2004. Image Processing with ImageJ. Biophotonics International. 11(7): 36-42.

Ae, N., Arihara, J., Okada, K., Yoshihara, T., and Johansen, C. 1990. Phosphorus uptake by Pigeon Pea and its role in cropping systems of the Indian subcontinent. Science 248(4954): 477-480.

Aerts, R., and Chapin, F.S. 2000. The mineral nutrition of wild plants revisited: A re-evaluation of processes and patterns. In Advances in Ecological Research, Vol 30. Edited by A.H. Fitter and D.G. Raffaelli. pp. 1-67.

Ayala Torales, A.T., Deregibus, V.A., and Moauro, P.R. 2000. Differential response of forage legumes to phosphorus application. New Zealand Journal of Agricultural Research 43(4): 473-480.

Bell, T.L., and Ojeda, F. 1999. Underground starch storage in Erica species of the Cape Floristic Region - differences between seeders and resprouters. New Phytologist 144(1): 143-152.

Bloom, A.J., Chapin, F.S., and Mooney, H.A. 1985. Resource limitation in plants - An economic analogy. Annual Review of Ecology and Systematics 16: 363-392.

Briffa, K.R. and Jones, P.D. 1990. Basic chronology statistics and assessment. In: Cook E.R., Kairiukstis L.A., eds. Methods of Dendrochronology. Applications in the Environmental Sciences. Dordrecht, Kluwer Academic Publishers: 137-152pp.

Briggs, J.M., and Knapp, A.K. 1995. Interannual variability in primary production in tallgrass prairie - climate, soil-moisture, topographic position, and fire as determinants of aboveground biomass. American Journal of Botany 82(8): 1024-1030.

Chapin, F.S., Schulze, E.D. and Mooney, H.A. 1990. The ecology and economics of storage in plants. Annual Review of Ecology and Systematics 21: 423-447.

Collins, S.L., Knapp, A.K., Briggs, J.M., Blair, J.M. and Steinauer, E.M. 1998. Modulation of diversity by grazing and mowing in native tallgrass prairie. Science 280(5364): 745-747.

Conkey, L.E. 1986. Red spruce tree-ring widths and densities in eastern North-America as indicators of past climate. Quaternary Research 26(2): 232-243. 
Cook, E., 1985. A time series analysis approach to tree ring standardization. University of Arizona, USA.

Corcuera, L., Camarero, J.J., and Gil-Pelegrin, E. 2004. Effects of a severe drought on Quercus ilex radial growth and xylem anatomy. Trees-Structure and Function 18(1): 83-92.

Dietz, H. 2002. Plant invasion patches - reconstructing pattern and process by means of herbchronology. Biological Invasions 4(3):211-222.

Dietz, H., and Schweingruber, F.H. 2002. Annual rings in native and introduced forbs of lower Michigan, USA. Canadian Journal of Botany 80(6): 642-649.

Dietz, H., and Ullmann, I. 1997. Age-determination of dicotyledonous herbaceous perennials by means of annual rings: Exception or rule? Annals of Botany 80(3): 377-379.

Dietz, H., and Ullmann, A. 1998. 'Ecological application of 'Herbchronology': Comparative stand age structure analyses of the invasive plant Bunias orientalis L. Annals of Botany 82(4): 471-480.

Dietz, H., von Arx, G., and Dietz, S. 2004. Growth patterns in two alpine forbs as preserved in annual rings of the roots: the influence of a snowbank gradient. Arctic, Antarctic, and Alpine Research 36(4): 591-597

Dietz, H., and von Arx, G. 2005. Climatic fluctuation causes large-scale synchronous variation in radial root increments of perennial forbs. Ecology 86(2): 327-333.

Franklin, R. S. 2013. Growth response of the alpine shrub, Linanthus pungens, to snowpack and temperature at a rock glacier site in the eastern Sierra Nevada of California, USA.

Quaternary International 310: 20-33.

Fritts H.C. 1976. Tree-Rings and Climate. New York, London, San Francisco. Academic Press: $567 \mathrm{pp}$.

Freeman, C.C. 1998. The flora of Konza prairie: a historical review and contemporary patterns. In Grassland Dynamics: Long-Term Ecological Research in Tallgrass Prairie. Edited by Knapp, A.K., Briggs, J.M., Hartnett, D.C. and Collins, S.L. Oxford University Press, New York. pp 69-80.

Hart, J.L., Clark, S.L., Torreano, S.J., and Buchanan, M.L. 2012. Composition, structure, and dendroecology of an old-growth Quercus forest on the tablelands of the Cumberland Plateau, USA. Forest Ecology and Management 266: 11-24.

Hartman, K.M., and McCarthy, B.C. 2007. A dendro-ecological study of forest overstorey productivity following the invasion of the non-indigenous shrub Lonicera maackii. Applied Vegetation Science 10(1): 3-14. 
Dee, J. D. and Palmer, M. W. Application of herb-chronology in the U.S. tallgrass prairie

Hayden, B. 1998. Regional climate and the distribution of tallgrass prairie. In Grassland Dynamics: Long-Term Ecological Research in Tallgrass Prairie. Edited by Knapp, A.K., Briggs, J.M., Hartnett, D.C. and Collins, S.L. Oxford University Press, New York. pp 19-34.

Hui, D.F., and Jackson, R.B. 2006. Geographical and interannual variability in biomass partitioning in grassland ecosystems: a synthesis of field data. New Phytologist 169(1): 8593.

Kiaer, L.P., Weisbach, A.N. and Weiner, J. 2013. Root and shoot competition: a meta-analysis. Journal of Ecology 101(5): 1298-1312.

Knapp A.K., Fay, P.A., Blair, J.M., Collins, S.L., Smith, M.D., Carlisle, J.D. ,Harper, C.W., Danner, B.T., Lett, M.S. and McCarron, J.K. 2002. Rainfall variability, carbon cycling, and plant species diversity in a mesic grassland. Science 298(2): 202-205.

Knapp, A.K., Koelliker, J.K., Fahnestock, J.T. and Briggs, J.M. 1994. Water relations and biomass responses to irrigation across a topographic gradient in tallgrass prairie. In Proceedings of the Thirteenth North America Prairie Conference. Edited by Wickett, R.G., Lewis, P.D., Woodliffe A. and Pratt, P. pp. 215-220.

Knapp, A. K. and Seastedt, T. R. 1998. Grasslands, Konza prairie and long-term ecological research. Pp. 3-15. In Grassland dynamics: long-term ecological research in tallgrass prairie. Edited by Knapp, A. K., Briggs, J. M., Hartnett, D. C. and Collins, S. L. Oxford University Press, New York.

Knapp, A.K. and Smith, M.D. 2001. Variation among biomes in temporal dynamics of aboveground primary production. Science 291(5503): 481-484.

Lacointe, A. 2000. Carbon allocation among tree organs: A review of basic processes and representation in functional-structural tree models. Annals of Forest Science 57(5-6): 521533.

Lauenroth, W. K. and Dodd, J. L. 1979. Response of native grassland legumes to water and nitrogen treatments. Journal of Range Management 32(4): 292-294.

Liu, Y. B. and Zhang, Q. B. 2010. Effect of climate on the growth of annual rings in the main roots of perennial forbs in an Inner Mongolian semi-arid grassland, China. Journal of Vegetation Science 21(5): 899-907.

Luo, Y.Q., Sherry, R., Zhou, X.H., and Wan, S.Q. 2009. Terrestrial carbon-cycle feedback to climate warming: experimental evidence on plant regulation and impacts of biofuel feedstock harvest. Global Change Biology Bioenergy 1(1): 62-74. 
Dee, J. D. and Palmer, M. W. Application of herb-chronology in the U.S. tallgrass prairie

Matisons, R., Elferts, D., and Brumelis, G. 2012. Changes in climatic signals of English oak treering width and cross-section area of earlywood vessels in Latvia during the period 19002009. Forest Ecology and Management 279: 34-44.

McCarthy, M.C., and Enquist, B.J. 2007. Consistency between an allometric approach and optimal partitioning theory in global patterns of plant biomass allocation. Functional Ecology 21(4): 713-720.

Mendivelso, H.A., Camarero, J.J., Obregon, O.R., Gutierrez, E. and Toledo, M. 2013. Differential growth responses to water balance of coexisting deciduous tree species are linked to wood density in a Bolivian tropical dry forest. Plos One 8(10).

Nippert, J.B. and A.K. Knapp. 2007. Soil water partitioning contributes to species coexisting in tallgrass prairie. Oikos 116(6): 1017-1029.

Olano JM, Eugenio M \& Escudero A. 2011. Site effect is stronger than species identity in driving demographic responses of Helianthemum (Cistaceae) shrubs in gypsum environments. American Journal of Botany 98 (6): 1016-1023.

Olano, J.M., Almeria, I., Eugenio, M., and von Arx, G. 2013. Under pressure: how a Mediterranean high-mountain forb coordinates growth and hydraulic xylem anatomy in response to temperature and water constraints. Functional Ecology 27(6): 1295-1303.

Ojima, D.S., Schimel, D.S., Parton, W.J., and Owensby, C.E. 1994. Long-term and short-term effects of fire on nitrogen cycling in tallgrass prairie. Biogeochemistry 24(2): 67-84

Pergl, J., Perglova, I., Pyšek, P., and Dietz, H. 2006. Population age structure and reproductive behavior of the monocarpic perennial Heracleum mantegazzianum (Apiaceae) in its native and invaded distribution ranges. American Journal of Botany 93(7): 1018-1028.

Perkins, D.L., Parks, C.G., Dwire, K.A., Endress, B.A., and Johnson, K.L. 2006. Age structure and age-related performance of sulfur cinquefoil (Potentilla recta). Weed Science 54(1): 8793.

Preibisch, S., Saalfeld, S. and Tomancak, P. 2009, Globally optimal stitching of tiled 3D microscopic image acquisitions, Bioinformatics 25(11):1463-1465.

R Core Team. 2015. R: A language and environment for statistical computing. R Foundation for Statistical Computing, Vienna, Austria.

Reed, S.C., Seastedt, T.R., Mann, C.M., Suding, K.N., Townsend, A.R., and Cherwin, K.L. 2007. Phosphorus fertilization stimulates nitrogen fixation and increases inorganic nitrogen concentrations in a restored prairie. Applied Soil Ecology 36(2-3): 238-242.

Rice, C.W., T.C. Todd, J.M. Blair, T.R. Seastedt, R.A. Ramundo, and G.W.T. Wilson. 1998. 
Dee, J. D. and Palmer, M. W. Application of herb-chronology in the U.S. tallgrass prairie

Belowground biology and processes. In Grassland Dynamics: Long-Term Ecological Research in Tallgrass Prairie. Edited by Knapp, A.K., Briggs, J.M., Hartnett, D.C. and Collins, S.L. Oxford University Press, New York. pp 244-264.

Salisbury, F. B. and Ross, C.W. 1992. Plant Physiology. 4th Edition. Wadsworth Publishing Co., Belmont, CA. 682 pp.

Schweingruber, F., Borner, A. and Schulze, E. D. 2011. Atlas of stem anatomy in herbs, shrubs, and trees. Vol. 1. Berlin, Heidelberg, Springer Verlag.

Smith, V.H. 1992. Effects of nitrogen-phosphorus supply ratios on nitrogen-fixation in agricultural and pastoral ecosystems. Biogeochemistry 18(1): 19-35.

Sprent, J.I., and Raven, J.A. 1985. Evolution of nitrogen-fixing symbioses. Proceedings of the Royal Society of Edinburgh Section B-Biological Sciences 85: 215-237.

Towne, E.G., and Knapp, A.K. 1996. Biomass and density responses in tallgrass prairie legumes to annual fire and topographic position. American Journal of Botany 83(2): 175-179.

Turner, C.L. and Knapp, A.K. 1996. Responses of a C-4 grass and three C-3 forbs to variation in nitrogen and light in tallgrass prairie. Ecology 77(6): 1738-1749.

Voelker, S.L., Noirot-Cosson, P.E., Stambaugh, M.C., McMurry, E.R., Meinzer, F.C., Lachenbruch, B., and Guyette, R.P. 2012. Spring temperature responses of oaks are synchronous with North Atlantic conditions during the last deglaciation. Ecological Monographs 82(2): 169-187.

von Arx, G., Archer, S.R., and Hughes, M.K. 2012. Long-term functional plasticity in plant hydraulic architecture in response to supplemental moisture. Annals of Botany 109(6):10911100 .

von Arx, G. and Dietz, H. 2006. Growth rings in the roots of temperate forbs are robust annual markers. Plant Biology 8(2): 224-233.

von Arx, G., Edwards, P. J. and Dietz, H. 2006. Evidence for life history changes in high altitude populations of three perennial forbs. Ecology 87(3): 665-674.

Wardlaw, I.F. 1990. Tansley Review NO 27 - The control of carbon partitioning in plants. New Phytologist 116(3): 341-381.

Weese, D. J., Heath, K. D., Dentinger, B.T.M. and Lau, J.A. 2015. Long-term nitrogen addition causes the evolution of less-cooperative mutualists. Evolution 69 (3): 631-642. 
Dee, J. D. and Palmer, M. W. Application of herb-chronology in the U.S. tallgrass prairie

Xu, X., Niu, S.L., Sherry, R.A., Zhou, X.H., Zhou, J.Z., and Luo, Y.Q. 2012. Interannual variability in responses of belowground net primary productivity (NPP) and NPP partitioning to long-term warming and clipping in a tallgrass prairie. Global Change Biology 18(5): 1648-1656.

Zhou, X.H., Fei, S.F., Sherry, R., and Luo, Y.Q. 2012. Root Biomass Dynamics Under Experimental Warming and Doubled Precipitation in a Tallgrass Prairie. Ecosystems 15(4): 542-554. 
Dee, J. D. and Palmer, M. W.

Application of herb-chronology in the U.S. tallgrass prairie

\section{Tables and Figures}

Table 1. Intra- and inter- treatment series correlations for each of the three species. Top part of the table shows the intra- and inter- treatment series correlations for the fertilization treatments while the bottom part shows the same for the irrigation transects. Values that are $>0.500$ are bolded, signifying a strong intra- or inter- treatment series correlation. Ring widths were not transformed prior to correlation. Sample size represents the number of individuals included in each respective pairwise correlation.

\begin{tabular}{|c|c|c|c|c|}
\hline & \multicolumn{3}{|c|}{ Intra-treatment correlation } & \multirow[t]{2}{*}{ Inter-treatment correlatior } \\
\hline & Control & $\underline{P}$ & $\underline{N P}$ & \\
\hline Asclepias syriaca & $0.1999(n=10)$ & $0.0485(n=20)$ & $0.1808(n=16)$ & $0.1385(n=46)$ \\
\hline Dalea purpurea & $0.2146(n=23)$ & $0.3505(n=11)$ & $x$ & $0.2973(n=34)$ \\
\hline Lespedeza capitata & $0.5865(n=20)$ & $0.5345(n=16)$ & $\mathrm{x}$ & $0.5212(n=36)$ \\
\hline & \multicolumn{3}{|c|}{ Irrigation-intra correlation } & $\underline{\text { Irrigation inter-treatment }}$ \\
\hline & Control & & Irrigated & \\
\hline Lespedeza capitata & $0.2217(n=18)$ & & $0.0544(n=18)$ & $0.2061(n=36)$ \\
\hline
\end{tabular}


Figure 1. Root collars of a) Lespedeza capitata and b) Asclepias syriaca. Approximately seven growth rings are visible in $L$. capitata, while ten are visible in $A$. syriaca. Specimens were stained with Toluidine Blue to help enhance ring boundaries. Proliferation of bands of earlywood-like vessels (larger in size and density compared to latewood vessels) were used to delineate ring borders. In the case of $A$. syriaca, shown here is the post-image processing in Image J to assign years from the outer to the most inner ring. Note the deterioration of the older rings in L. capitata, thus rendering unreliable age estimation in most individuals of this species as well as D. purpurea.

Figure 2. Yearly sample depth for A) Dalea purpurea, Asclepias syriaca, and Lespedeza capitata in the fertilization treatments and B) Lespedeza capitata in the irrigation transect experiment. All analyses were ceased around 2008 - 2007 due to the low sample depth for the years prior.

Figure 3. Average ring widths $(95 \% \mathrm{CI})$ per year as a function of nutrition treatment for $\mathbf{A}$. Asclepias syriaca and B. Lespedeza capitata. Letters denote significantly different treatments per year via post-hoc comparisons. The line graph projected above the bar graph shows the average monthly temperature between April and June per year to highlight the relationship with annual ring widths. This relationship was significant $(\mathrm{P}<0.05)$ for both species, with the correlation coefficient $=-0.184$ for $A$. syriaca and -0.217 for $L$. capitata. Precipitation (not shown) was not significant in either case. Late season climatic variables were also not significant.

Figure 4. Average ring widths $(95 \% \mathrm{CI})$ per year as a function of irrigation treatment for $L$. capitata. Letters denote significantly different treatments per yea via post-hoc comparisons. The line graphs projected above the bar graph show the average monthly temperature and rainfall between April and June per year to highlight the relationship with annual ring widths. Climatic variables were significant $(\mathrm{P}<0.05)$ with correlation coefficients $=0.227$, and -0.223 for average monthly rainfall and temperature respectfully. Late season climatic variables were not significant. 

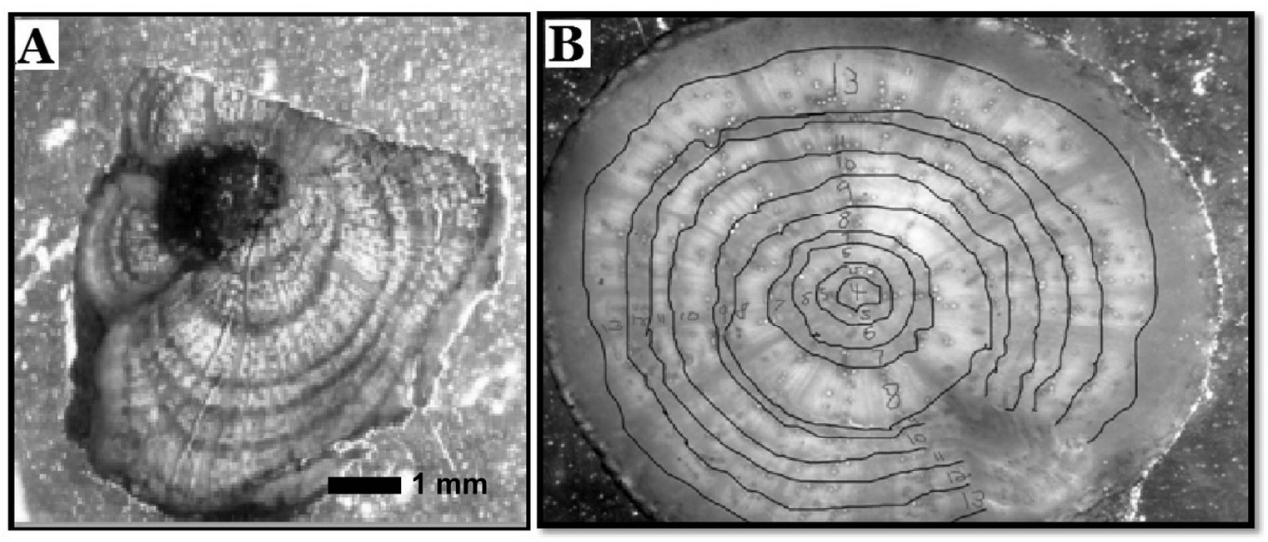

Figure 1. Root collars of a) Lespedeza capitata and b) Asclepias syriaca. Approximately seven growth rings are visible in L. capitata, while ten are visible in A. syriaca. Specimens were stained with Toluidine Blue to help enhance ring boundaries. Proliferation of bands of earlywood-like vessels (larger in size and density compared to latewood vessels) were used to delineate ring borders. In the case of A. syriaca, shown here is the post-image processing in Image] to assign years from the outer to the most inner ring. Note the deterioration of the older rings in L. capitata, thus rendering unreliable age estimation in most individuals of this species as well as D. purpurea.

$140 \times 60 \mathrm{~mm}(300 \times 300$ DPI $)$ 

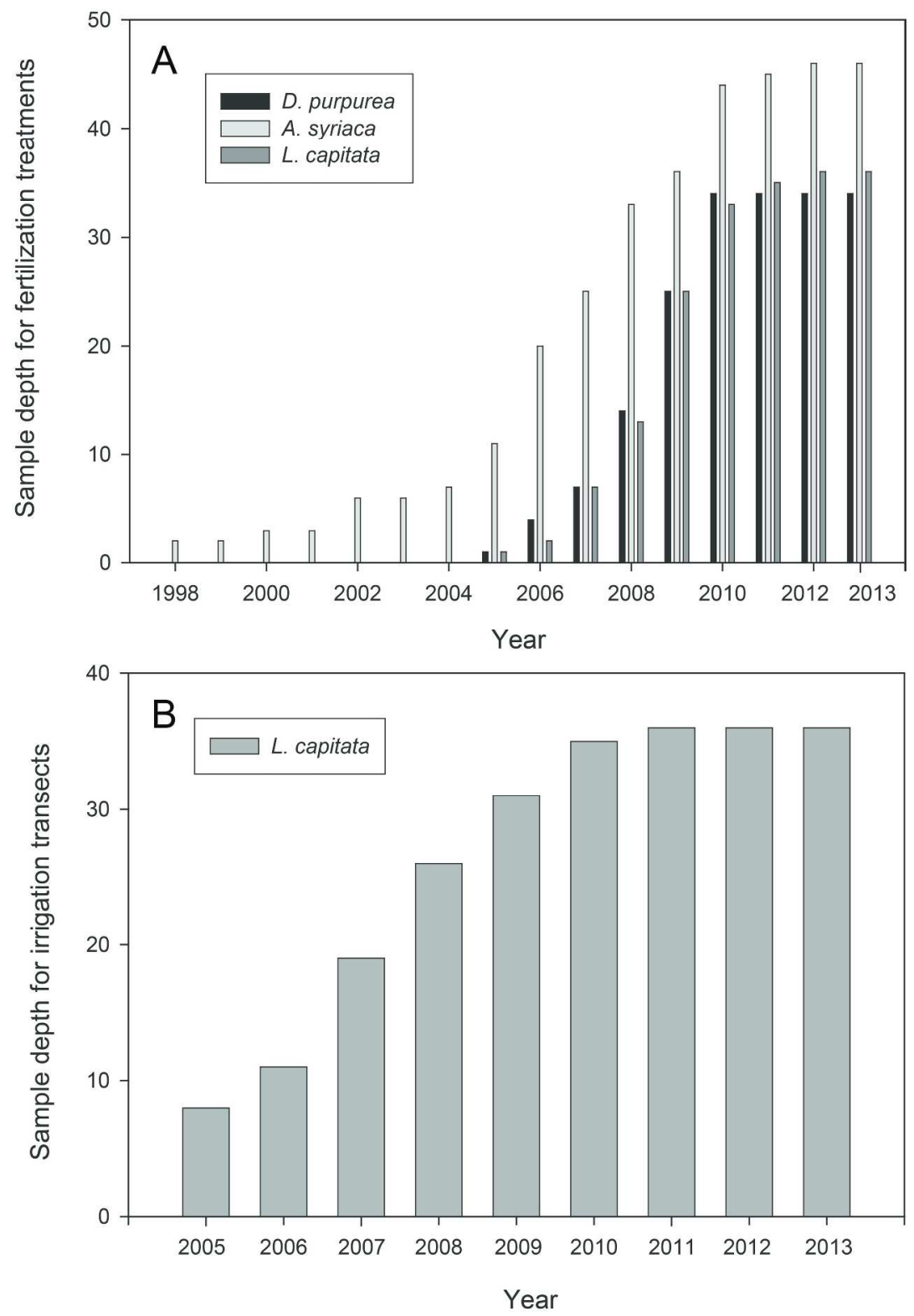

Figure 2. Yearly sample depth for A) Dalea purpurea, Asclepias syriaca, and Lespedeza capitata in the fertilization treatments and B) Lespedeza capitata in the irrigation transect experiment. All analyses were ceased around $2008-2007$ due to the low sample depth for the years prior. $214 \times 313 \mathrm{~mm}(300 \times 300$ DPI $)$ 


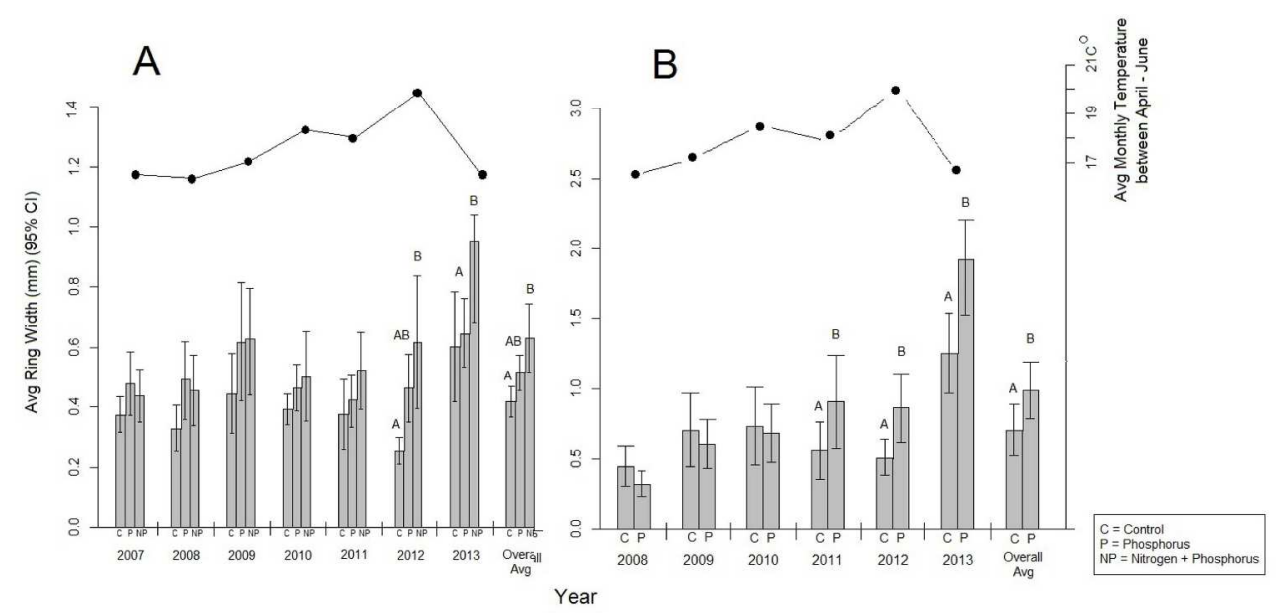

Figure 3. Average ring widths $(95 \% \mathrm{CI})$ per year as a function of nutrition treatment for A. Asclepias syriaca and B. Lespedeza capitata. Letters denote significantly different treatments per year via post-hoc comparisons. The line graph projected above the bar graph shows the average monthly temperature between April and June per year to highlight the relationship with annual ring widths. This relationship was significant $(P<0.05)$ for both species, with the correlation coefficient $=-0.184$ for $A$. syriaca and -0.217 for L. capitata. Precipitation (not shown) was not significant in either case. Late season climatic variables were also not significant.

207×107mm (300 x 300 DPI) 


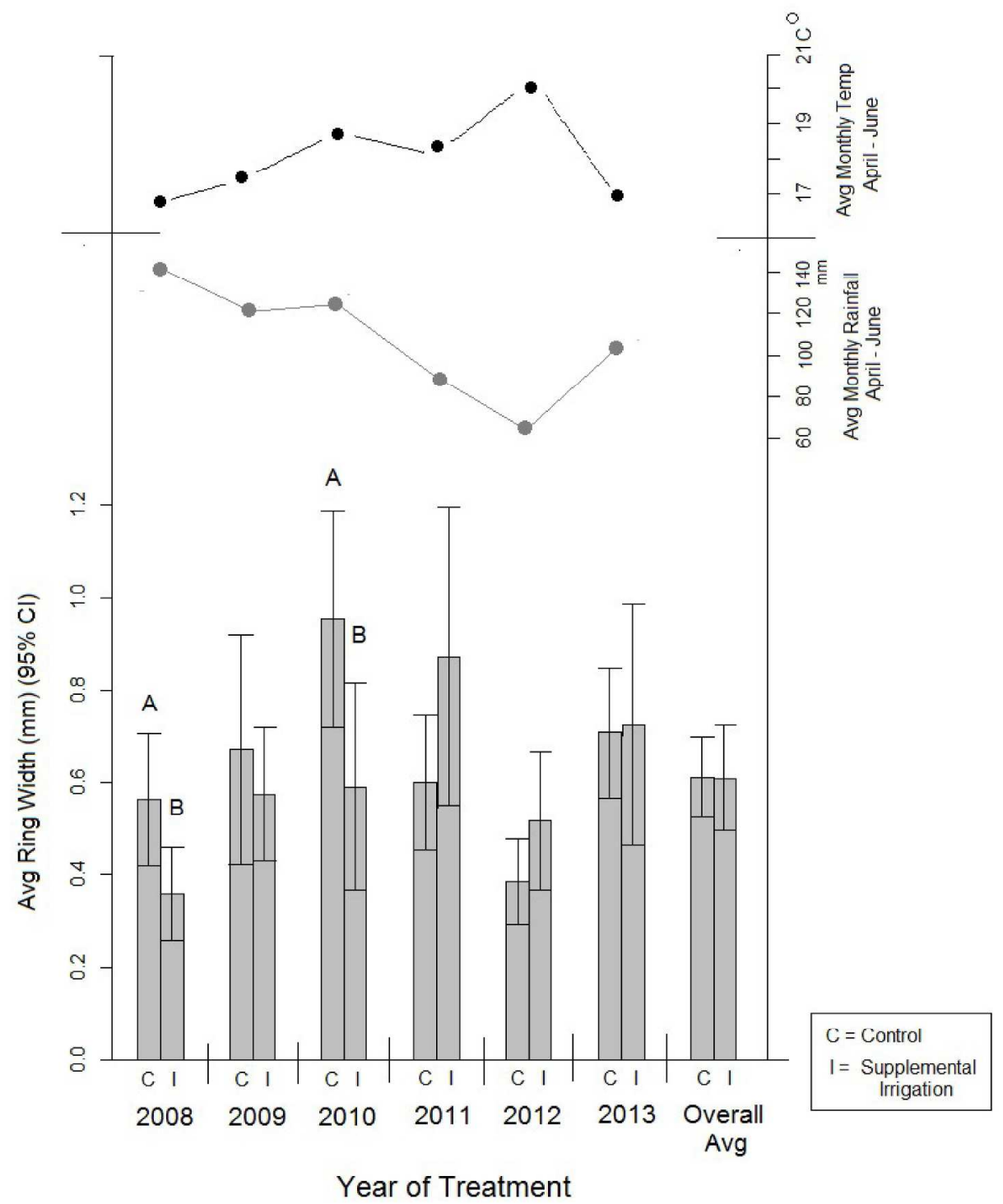

Figure 4. Average ring widths ( $95 \% \mathrm{CI}$ ) per year as a function of irrigation treatment for L. capitata. Letters denote significantly different treatments per yea via post-hoc comparisons. The line graphs projected above the bar graph show the average monthly temperature and rainfall between April and June per year to highlight the relationship with annual ring widths. Climatic variables were significant $(P<0.05)$ with correlation coefficients $=0.227$, and -0.223 for average monthly rainfall and temperature respectfully. Late season climatic variables were not significant.

$$
279 \times 340 \mathrm{~mm} \text { (300 x } 300 \text { DPI) }
$$

